\title{
Quality Assessment of Cannabidiol Rich Cannabis Extracts Purchased on the Internet
}

ISSN: 2578-0042

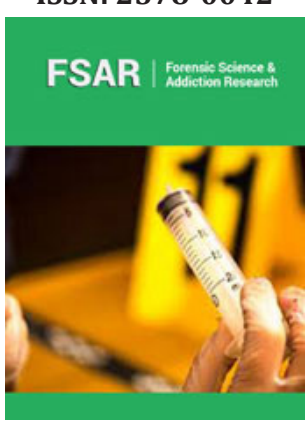

*Corresponding author: Serge Schneider, National Health Laboratory, 1 rue Louis Rech, L-3555 Dudelange, Luxembourg

Submission: 侮 May 05, 2021

Published: 笽 May 21, 2021

Volume 5 - Issue 3

How to cite this article: Anaïs Rodrigues, Carole Dauberschmidt, Claude Schummer, Georges Dahm, Serge Schneider. Quality Assessment of Cannabidiol Rich Cannabis Extracts Purchased on the Internet. Forensic Sci Add Res. 5(3). FSAR. 000620. 2021.

DOI: 10.31031/FSAR.2021.05.000620

Copyright@ Serge Schneider, This article is distributed under the terms of the Creative Commons Attribution 4.0 International License, which permits unrestricted use and redistribution provided that the original author and source are credited.
Anaïs Rodrigues, Carole Dauberschmidt, Claude Schummer, Georges Dahm and Serge Schneider*

National Health Laboratory, 1 rue Louis Rech, L-3555 Dudelange, Luxembourg

\section{Abstract}

Research shows that cannabis has a beneficial impact on many different health issues and, as a consequence, concentrated cannabis derived products are becoming increasingly popular. Above all, high Cannabidiol (CBD) and low Tetrahydrocannabinol (THC) extracts are aggressively marketed by many vendors via internet-based shops. As with "classical" medication or food supplements, assessment of product safety is an important issue. Because many different non-standardized production methods are used and no international accepted technical verification procedures of the final products are yet available, the quality of CBD oils generally cannot be guaranteed.

In this study, cannabinoid, terpene, pesticide, solvent and metal content of 24 CBD rich extracts purchased from several internet vendors were investigated. Furthermore, consumer information given on the internet site or as package insert is also discussed. Most of the samples had substandard consumer information and CBD concentrations below the proclaimed values. Terpene concentrations were highly variable, pesticides were detected in three samples and residual extraction solvents were detected in four samples. Metals were present at low, non-toxic levels in all samples. Considering the growing popularity of medical cannabis and of online shops consumer education is important and systematic quality testing for cannabis extracts should be mandatory.

Keywords: Cannabis extracts; Cannabinoid content; Terpenes; Pesticides; Metals; Solvents; Online vendors

Abbreviations: CBD: Cannabidiol; CBDA: Cannabidiol Acid; CBG: Cannabigerol; CBGA: Cannabigerol Acid; CBN: Cannabinol; THC: Tetrahydrocannabinol; CYP: Cytochrome P; DMA: Direct Mercury Analyser; GC/MS: Gas Chromatography Coupled to Mass Spectrometry; GC/MS/MS: Gas Chromatography Coupled to Tandem Mass Spectrometry; HPLC/UV: High Performance Chromatography Coupled to Ultraviolt Detection; HS/GC/MS: Head Space Gas Chromatography Coupled to Mass Spectrometry; LC/MS/MS: Liquid Chromatography Coupled to Tandem Mass Spectrometry; LLOQ: Lower Limit of Quantification; LOD: Limit of Detection; MRM: Multiple Reaction Monitoring; PDA: Photodiode Array Detector; PTFE: Polytetrafluorethen; S/N: Signal to Noise Ratio; THCA: Tetrahydrocannabinol Acid

\section{Introduction}

Cannabis counts among the oldest known medicines and nutrients of humanity. For thousands of years it has been used in East and South East Asia and much later in Europe and North America. However, with the development of chemical and pharmaceutical industries in the $19^{\text {th }}$ century and because of political and economic reasons at the beginning of the $20^{\text {th }}$ century, it has been first marginalized and later banned. Recent research however shows that cannabinoids in general and Cannabidiol (CBD) in particular as well as other cannabis ingredients, such as terpenes, have beneficial impact on many health issues, including cancer, psychosis, neuropathic pain, nausea, sclerosis, arthritis, fibromyalgia, Parkinson disease, anxiety, autism [1-4]. Additionally, CBD is generally well tolerated [5,6], it is not psychotropic, adverse events and side effects are rare and seem to resolve on their own with time. Consequently, more and more countries worldwide legalize or decriminalize cannabis for medical use.

Mono, di and sesquiterpenes count among the largest group of phytochemicals and they give the distinct flavor and aroma to fruits and plants. In the case of medical cannabis, much attention has been given to the theory of the "entourage effect" first described by Russo [7], outlining potential potentiation between terpenes and cannabinoids making the "whole plant medicine" more effective than the sum of the effects of the single compounds. Research supports these findings and shows that the terpenes have a "broad range of the biological properties (...) including cancer chemopreventive effects, antimicrobial, antifungal, antiviral, 
anti-hyperglycemic, anti-inflammatory, and antiparasitic activities" $[8,9]$. Many terpenes however are often volatilizing at, or slightly above, room temperature. In order to prevent this volatilization, cannabis extracts are generally prepared using supercritical $\mathrm{CO}_{2}$ based methods instead of the more classical solvent extraction methods.

Meanwhile, the internet is becoming a popular source of medical advice and an online pharmacy for standard and exotic pharmaceuticals or food supplements [10]. Beside the ethical, legal and regulatory aspects of this trade, major challenges are public health issues such as manufacturing and distribution practice, patient information and, above all, product quality $[11,12]$. However, often, easy ordering, and low prices are of higher priority than product quality for buyers. Even if regulation efforts have been made, quality control of products sold on the internet remains a major concern [13]. In fact, internet drug outlets may be illegitimate or illegal [14] making quality control efforts illusionary.

In this project, a total of 24 CBD oils purchased from vendors from seven European countries were analyzed. The objectives were to access user/patient information provided to purchasers and to assess the overall CBD oil quality. Cannabinoid content, i.e. cannabidiol (CBD), Cannabidiolic Acid (CBDa), Tetrahydrocannabinol (THC), Tetrahydrocannabinolic Acid (THCa), Cannabinol (CBN), Cannabigerol (CBG), cannabigerolic acid (CBGa), terpene content $(\alpha$-pinene, $\beta$-myrcene, linalool, $\beta$-caryophyllene, humulene, guaiol, limonene), solvents, pesticides and metal were investigated.

\section{Material and Methods}

\section{CBD oils}

CBD oils were ordered from 25 online vendors. Twenty-four samples were finally bought, one vendor refused to sell products to an analytical laboratory. Samples were bought from Austria, France, Germany, Great Britain, Luxembourg, Netherlands and Spain. All samples were received in good condition in three days to two weeks after ordering. They were all stored at $5^{\circ} \mathrm{C}$ in the dark, even if three vendors recommended storing at room temperature.

\section{Analytical methods}

Cannabinoid and terpene content were determined using validated HPLC/UV and GC/MS methods, respectively. Validation parameters included the determination of the linearity, intraday precision and accuracy, Limit of Detection (LOD) and Lower Limit of Quantification (LLOQ). The LOD was defined as a signal to noise ratio equal of above three and the LLOQ as a signal to noise ratio equal or above 10. A six-point calibration curve was established before each series of analysis. For cannabinoid dosage, 50 to $100 \mathrm{mg}$ of oil were dissolved in $20 \mathrm{~mL}$ of ethanol, homogenized and diluted again in HPLC buffer (20 $\mathrm{mM} \mathrm{KH}_{2} \mathrm{PO}_{4} \mathrm{pH} 2.18 /$ acetonitrile, 35/65, v/v) to obtain concentrations in the $0.1 \mathrm{mg} / \mathrm{L}$ range. $10 \mu \mathrm{L}$ of this solution were injected into the HPLC/UV system. Analyses were carried out on a reverse phase high performance liquid chromatography system coupled to UV detector (Dionex Ultimate 3000 RS HPLC/
UV, Thermo Fisher, Waltham, USA). Chromatographic separation was achieved on an Acclaim ${ }^{\mathrm{TM}}$ Polar Advantage II column $(100 \mathrm{~mm}$ x $2.4 \mathrm{~mm} \times 2.2 \mu \mathrm{m}$ ). Detection was obtained using a photodiode array detector (PDA, 200-360nm). Quantification wavelength was 209nm for decarboxylated cannabinoids and 223nm for carboxylated cannabinoids. Oven temperature was set at $50^{\circ} \mathrm{C}$, chromatographic conditions were developed using HPLC quality water containing $20 \mathrm{mM} \mathrm{KH}_{2} \mathrm{PO}_{4}$ (eluent $\mathrm{A}$ ) and acetonitrile (eluent B). Chromatographic conditions were $39 \%$ eluent A/61\% eluent $B$ for $4 \mathrm{~min}$ followed by a linear gradient $61-90 \%$ B in 3min. Returning to initial conditions was achieved in $0.4 \mathrm{~min}$. Equilibration time was $2 \mathrm{~min}$ and the flow rate was fixed at $0.85 \mathrm{~mL} / \mathrm{min}$ over the whole run.

A 6 points linear calibration curve was established before analysis of the real case samples. Absolute amounts injected were 0 (blank), 10, 25, 50, 75 and 100ng of the cannabinoids in eluent A. The coefficient of determination $\left(\mathrm{r}^{2}\right)$ was $>0.99$ and resolution was $>1.5$ for all cannabinoids. Coefficient of variation and accuracy bias were $<15 \%$. In real case samples, a relative standard deviation of the relative peak purity index $<5 \%$ was considered for positive detection and a $\mathrm{S} / \mathrm{N}>10$ for quantification of cannabinoids. All analyses were performed in duplicate; the average of the two results was retained.

For terpene determination, 100 to $150 \mathrm{mg}$ of oil were dissolved in 5 or $10 \mathrm{~mL}$ of ethyl acetate, homogenized and diluted again from 10 to 100 times to fit into calibration ranges. Butyl paraben (at a concentration of about $10 \mathrm{mg} / \mathrm{L}$ ) was added as internal standard to each sample before analysis. $1 \mu \mathrm{L}$ of the solution was injected into the GC/MS system (7890A gas chromatography, equipped with an automatic injector AS 7693 and coupled to a 5975C mass spectrometer, Agilent Technologies, Waldbronn, Germany). Chromatographic separation was achieved on a HP-5 MS ( $5 \%$ phenyl methyl siloxane) column ( $30 \mathrm{~m} \times 0.25 \mathrm{~mm} \times 0.25 \mu \mathrm{m})$ with helium as vector gas. Detection was done in scan mode (m/z 50-600). Injector temperature was $250^{\circ} \mathrm{C}$. Initial chromatographic conditions were $70^{\circ} \mathrm{C}$ for $1 \mathrm{~min}$ then $25^{\circ} \mathrm{C} / \mathrm{min}$ to $190^{\circ} \mathrm{C}$ and then $10^{\circ} \mathrm{C} / \mathrm{min}$ to $310^{\circ} \mathrm{C}$ for $25 \mathrm{~min}$. Flow rate was fixed at $1.2 \mathrm{~mL} / \mathrm{min}$ over the whole run. A 6 points linear calibration curve was established before analysis of the real case samples. $1 \mu \mathrm{L}$ of solutions of $0,20,100,225,350$ and $450 \mu \mathrm{L}$ of the terpenoids content in $1 \mathrm{~mL}$ ethyl acetate (at a concentration of about $10 \mathrm{mg} / \mathrm{L}$ ) with $100 \mu \mathrm{L}$ of butyl paraben as internal standard (at a concentration of about $10 \mathrm{mg} / \mathrm{L}$ ) was injected. $\mathrm{r}^{2}$ was $>0.98$ and resolution was $>1.5$ for all terpenes. Coefficient of variation and accuracy bias were $<15 \%$. In real case samples, a $\mathrm{S} / \mathrm{N}>3$ was considered for positive detection and a $\mathrm{S} / \mathrm{N}$ $>10$ for quantification. LOD was $0.2 \mathrm{ng} / \mu \mathrm{L}$.

Determination of residual solvent was carried out on a Head Space GC/MS system (HS/GC/MC) consisting of a $6890 \mathrm{~N}$ gas chromatography, equipped with a head space sampler 7697 A and coupled to a 5975C mass spectrometer (Agilent Technologies, Waldbronn, Germany). Chromatographic separation was achieved on a DB-624 (bonded and cross-linked) column (30m x $0.32 \mathrm{~mm} \times$ $1.80 \mu \mathrm{m}$ ) with helium as vector gas. Detection was done in scan mode scanning $\mathrm{m} / \mathrm{z}$ from 25 to 300 . Oven temperature was fixed at $85^{\circ} \mathrm{C}$. 
$\mathrm{GC} / \mathrm{MS}$ injector temperature was $250^{\circ} \mathrm{C}$. Initial chromatographic conditions were $40^{\circ} \mathrm{C}$ for $4 \mathrm{~min}$ then $12.5^{\circ} \mathrm{C} / \mathrm{min}$ to $160^{\circ} \mathrm{C}$ and then $100^{\circ} \mathrm{C} / \mathrm{min}$ to $220^{\circ} \mathrm{C}$ for $0.8 \mathrm{~min}$. Flow rate was fixed at $2.48 \mathrm{ml} / \mathrm{min}$ over the whole run. A mass of 100 to $150 \mathrm{mg}$ of oil was introduced in $10 \mathrm{~mL}$ head space vial with $100 \mu \mathrm{L}$ of a 1-butanol solution $(1 \mathrm{~mL} / \mathrm{L})$ as internal standard. A 4 points linear calibration curve was established before analysis of the real case samples. Solutions of 0 (blanc with internal standard), 1, 2.5 and $5 \mathrm{~mL} / \mathrm{L}$ of the solvent in $100 \mathrm{~mL} \mathrm{H}_{2} \mathrm{O}$ with $100 \mu \mathrm{L}$ of 1-butanol as internal standard were injected in split mode with a ratio of 40: 1 . Samples with $\mathrm{S} / \mathrm{N}>10$ were dosed.

For pesticide determination, the EN 15662 method for pesticide analysis in foods of plant origin with QuEChERS extraction was adapted for analysis of the oils. The adaption consisted in taking $1 \mathrm{~g}$ of sample instead of $10 \mathrm{~g}$. Cleanup was done using PSA - carbon black mix of 19:1 (w/w). The sample was mixed with $10 \mathrm{~mL}$ acetonitrile, and shaken for 1 minute. Then, a mixture of salts was added (4. $\mathrm{MgSO}_{4} ; 1 \mathrm{~g} \mathrm{NaCl} ; 1 \mathrm{~g}$ sodium citrate and $0.5 \mathrm{~g}$ disodium citrate sesquidydrate), and shaken for 1 minute, centrifuged for 5minutes at $4000 \mathrm{rpm}$. $1 \mathrm{ml}$ of the upper layer was mixed with the internal standard (triphenyl phosphate) and injected into the analytical systems. A total of 177 pesticides were scanned using LC/MS/MS or GC/MS/MS. LC-MS/MS analyses of pesticides were carried out on an Aquity ultra-performance liquid chromatography system (Waters, Zellik, Belgium). Chromatographic separation was achieved on an Aquity UPLC HSS T3 column $(100 \mathrm{~mm}$ x $2.1 \mathrm{~mm}$ x $1.8 \mu \mathrm{m})$. A linear multi-step solvent gradient was applied with the solvents A (water, $0.02 \%$ formic acid) and B (acetonitrile, $0.02 \%$ formic acid). The gradient consisted of $0-16 \mathrm{~min} 100-0 \%$ (A); $16-$ $18 \mathrm{~min}, 100 \%$ (B); $18-20 \mathrm{~min}, 0-100 \%$ (A). The flow was set to
$0.4 \mathrm{~mL} / \mathrm{min}$. The injection volume was $1 \mu \mathrm{l}$. The temperature of the sample chamber was $15^{\circ} \mathrm{C}$ and the temperature of the column oven was set at $40^{\circ} \mathrm{C}$. MS/MS measurements were carried out on a XevoTQS unit (Waters, Zellik, Belgium) in Multiple Reaction Monitoring (MRM) mode. MassLynx software (Waters) was used to detect pesticides in monitored data. Reported limit was at $0,1 \mathrm{mg} /$ kg. Semi-quantitation of identified pesticides (propamocarb) was carried out in a second step with external calibration. CG/MS/MS analyses of pesticides were carried out on an Agilent 7000 Series triple Quad equipped with an HP-5MS (5\% phenyl methyl siloxane) column ( $30 \mathrm{~m} \times 0.25 \mathrm{~mm} \times 0.25 \mu \mathrm{m}$ ) in MRM mode. Screening of pesticides was done using Masshunter identification software. The reporting limit for all pesticides was $1 \mathrm{mg} / \mathrm{kg}$.

For metal determination the EN 13805:2014 (European Committee for Standardization, 2014) method was used. To $1 \mathrm{~g}$ of oil in a PTFE vessel, $4 \mathrm{~mL}$ of $\mathrm{HNO}_{3}(65 \%), 1 \mathrm{~mL}$ of $\mathrm{H}_{2} \mathrm{O}_{2}(31 \%)$ and $1 \mathrm{~mL}$ of $\mathrm{H}_{2} \mathrm{O}$ were added. The mixture was let to react for 5 minutes at room temperature and then heated over a 30minutes' gradient to $180^{\circ} \mathrm{C}$ using a Mars $5 \mathrm{X}$ press microwave. This temperature was maintained over 30 minutes. A volume of $1 \mathrm{~mL}$ of the obtained solution was diluted with $1 \mathrm{~mL}$ of internal standard $(10 \mathrm{ppb}$ of $\mathrm{Tb}$, $\mathrm{Y}$ and $\mathrm{Sc}$ in $5 \% \mathrm{HNO}_{3}$ ). Metal analyses (expect for mercury) were carried out in duplicate on an Agilent 7700x ICP-MS (Agilent Technologies, Waldbronn, Germany) in He collision cell modus and using external calibration $(0.05-100 \mu \mathrm{g} / \mathrm{L})$. Mercury analyses were carried out on a Milestone DMA-80 (Milestone Srl, Sorisole, Italy) using $30 \mathrm{mg}$ of sample with following parameters: quadratic calibration at $254 \mathrm{~nm}$, temperature program: $200^{\circ} \mathrm{C}$ for $1 \mathrm{~min}$; elution: $650^{\circ} \mathrm{C}, 60 \mathrm{~s}$, amalgam heating: $650^{\circ} \mathrm{C}, 12 \mathrm{~s}$, measurement time $30 \mathrm{~s}$. LOD for all metals was $0.01 \mu \mathrm{g} / \mathrm{g}$.

\section{Results and Discussion}

\section{Consumer information}

Table 1: Consumer information obtained from the vendors' internet site or as package insert.

\begin{tabular}{|c|c|c|c|c|c|c|}
\hline Oil n ${ }^{\circ}$ & $\begin{array}{l}\text { Cannabinoid } \\
\text { Labelling }\end{array}$ & $\begin{array}{l}\text { Batch } \\
\text { Number }\end{array}$ & $\begin{array}{l}\text { Expiration } \\
\text { Date }\end{array}$ & Storage Recommendation & Dosage Recommendation & $\begin{array}{c}\text { Information About Side } \\
\text { Effects }\end{array}$ \\
\hline 1 & yes & no & no & no & yes & no \\
\hline 2 & yes & yes & yes & no & yes & no \\
\hline 3 & yes & yes & yes & no & yes & no \\
\hline 4 & yes & yes & yes & no & yes & no \\
\hline 5 & yes & no & no & no & yes & yes \\
\hline 6 & yes & yes & yes & yes & no & no \\
\hline 7 & yes & no & yes & yes & yes & no \\
\hline 8 & yes & no & no & yes & no & no \\
\hline 9 & yes & yes & yes & no & yes & no \\
\hline 10 & yes & no & yes & no & yes & no \\
\hline 11 & yes & yes & yes & no & yes & no \\
\hline 12 & yes & yes & yes & yes & yes & no \\
\hline 13 & yes & yes & yes & yes & yes & yes \\
\hline 14 & yes & yes & yes & yes & yes & yes \\
\hline 15 & no & yes & yes & no & no & no \\
\hline
\end{tabular}




\begin{tabular}{|c|c|c|c|c|c|c|}
\hline 16 & yes & yes & yes & yes & yes & yes \\
\hline 17 & yes & yes & yes & yes & yes & no \\
\hline 18 & no & yes & no & no & no & no \\
\hline 19 & yes & yes & yes & no & no & no \\
\hline 20 & yes & yes & yes & yes & yes & no \\
\hline 21 & yes & yes & yes & yes & yes & no \\
\hline 22 & yes & yes & yes & yes & yes & yes \\
\hline 23 & yes & no & no & no & no & no \\
\hline 24 & yes & yes & yes & no & no & no \\
\hline
\end{tabular}

Vendor specifications and recommendations included in the product package or available on the respective internet sites are summarized in Table 1. All but two vendors (91.7\%) informed about the cannabinoid content. Over the 24 vendors, 18 (75.0\%) indicated a batch number; 19 (79.2\%) the expiration date; 11 (45.8\%) storage information and 17 (70.8\%) dosage recommendations. Even if dosage of CBD is highly individual and has to be adapted to each patient, general guidelines may help healthcare professionals and patients at the beginning of the therapy. Somnolence was mentioned as a potential side effect by one vendor $\left(n^{\circ} .5\right)$. Four vendors $\left(n^{\circ} .13\right.$, 14, 16 and 22) recommended avoiding CBD for pregnant women. All vendors who informed about the batch number also informed about an expiration date, but only four vendors (16.7\%) informed about all parameters listed in Table 1 . No vendor discussed possible drug interactions. Drug-drug interactions or overdosage is generally not considered a serious health issue for CBD, but CBD is known to be an inhibitor of the cytochrome P450 enzyme family $[15,16]$. This may result in higher levels and even toxicity of other drugs if consumed together with CBD. CBD also reduces blood pressure [17] which may be a positive health effect in some cases but has to be considered when simultaneously taking anti-hypertensive drugs. In addition, CYP3A4 and CYP2C19 have been identified as major contributors to CBD metabolism. Inhibitors of these enzymes may increase CBD levels whereas inducers may reduce CBD blood levels. Consumers should be made attentive to these effects and be asked to discuss the CBD intake with their doctor.

\section{Cannabinoid and terpene content}

In two samples ( $\mathrm{n}^{\circ} 15$ and 18), the cannabinoid concentrations were unknown and the results could not be compared to vendor claims. Seven samples (29.2\%) had CBD + CBDA concentrations within $10 \%$ of claimed values (range $90-110 \%$ ); eleven samples (45.8\%) had concentrations ranging from 75-90\%; four samples had concentrations ranging from $50-75 \%$ and one sample $\left(n^{\circ} .8\right)$ had a CBD concentration more than 5 times below the claimed concentration. One sample, the unlabeled one ( $\left.n^{\circ} .18\right)$, had THC concentration above $0.2 \% \mathrm{w} / \mathrm{w}$ (legal limit in most European countries). No CBN, the major THC degradation compound, was detected in the samples. For $50 \%$ of the samples no information about the extraction method used was available. CBDA, the carboxylated precursor of $\mathrm{CBD}$, was detected in 15 samples (62.5\%), concentration range was $0.01-5.24 \mathrm{w} / \mathrm{w} \%$. In one sample $\left(n^{\circ} .3\right)$ claiming "raw" (= low temperature) extraction, no CBDA was detected. The cannabinoid concentrations are summarized in Table 2.

Table 2: Cannabinoid labelling on CBD oils and laboratory results. Data expressed as the mean in percentage of dry starting material (w/w\%).

\begin{tabular}{|c|c|c|c|c|c|c|c|}
\hline Cannabis Oil $\mathbf{n}^{\circ}$ & Cannabinoids Labelling & CBD + CBDA & THC & THCA & CBG & CBGA & CBN \\
\hline 1 & CBD: 4 & 3,87 & 0,06 & $<\mathrm{LOD}$ & 0,02 & $<\mathrm{LOD}$ & $<$ LOD \\
\hline 2 & CBD: 2,75 & 2,17 & 0,03 & $<$ LOD & 0,01 & $<$ LOD & $<$ LOD \\
\hline 3 & CBD: 2,75 & 2,22 & 0,04 & $<$ LOD & 0,02 & $<$ LOD & $<$ LOD \\
\hline 4 & CBD + CBDA: 4 & 3,01 & 0,08 & $<$ LOD & 0,03 & $<$ LOD & $<$ LOD \\
\hline 5 & CBD: 2,5 & 2,1 & 0,05 & $<$ LOD & $<$ LOD & $<$ LOD & $<$ LOD \\
\hline 6 & CBD + CBDA: 3 & 2,46 & 0,01 & 0,03 & $<$ LOD & $<\mathrm{LOD}$ & $<$ LOD \\
\hline 7 & CBD + CBDA: 8 & 7,85 & 0,12 & $<$ LOD & 0,15 & 0,07 & $<$ LOD \\
\hline 8 & CBD: 25 & 4,79 & 0,13 & $<$ LOD & 0,01 & $<$ LOD & $<$ LOD \\
\hline 9 & CBD: 2,75 & 2,26 & 0,05 & $<$ LOD & 0,03 & $<$ LOD & $<$ LOD \\
\hline 10 & CBD: 1,5 & 1,19 & 0,04 & $<$ LOD & 0,02 & $<$ LOD & $<$ LOD \\
\hline 11 & CBD: 5 & 4,65 & 0,13 & $<\mathrm{LOD}$ & 0,04 & $<\mathrm{LOD}$ & $<$ LOD \\
\hline 12 & CBD: 4 & 3,58 & $<$ LOD & $<$ LOD & 0,04 & $<$ LOD & $<$ LOD \\
\hline 13 & CBD + CBDA: 5 & 4,14 & 0,06 & $<$ LOD & $<$ LOD & $<$ LOD & $<$ LOD \\
\hline 14 & CBD: 3 & 2,35 & 0,07 & $<$ LOD & 0,03 & $<$ LOD & $<$ LOD \\
\hline
\end{tabular}




\begin{tabular}{|c|c|c|c|c|c|c|c|}
\hline 15 & - & 3,3 & 0,1 & $<$ LOD & 0,08 & $<$ LOD & $<$ LOD \\
\hline 16 & CBD + CBDA: 5 & 3,99 & 0,12 & $<$ LOD & 0,03 & $<$ LOD & $<$ LOD \\
\hline 17 & CBD: 7 & 4,46 & 0,15 & $<$ LOD & 0,05 & $<$ LOD & $<$ LOD \\
\hline 18 & No labelling & 8,16 & 0,42 & 0,24 & 0,04 & 0,07 & $<$ LOD \\
\hline 19 & CBD: 3,88 & 2,9 & 0,09 & $<$ LOD & $<$ LOD & $<$ LOD & $<$ LOD \\
\hline 20 & CBD: 2,5 & 2,43 & $<$ LOD & $<$ LOD & 0,03 & $<$ LOD & $<$ LOD \\
\hline 21 & CBD: 4 & 3,7 & $<$ LOD & $<$ LOD & 0,04 & $<$ LOD & $<$ LOD \\
\hline 22 & CBD + CBDA: 10 & 7,18 & 0,15 & $<$ LOD & 0,06 & $<$ LOD & $<$ LOD \\
\hline 23 & CBD: 5,3 & 3,2 & 0,05 & 0,04 & 0,02 & $0,09<$ & $<$ LOD \\
\hline 24 & CBD: 10 & 10,04 & $<$ LOD & $<$ LOD & $<$ LOD & $<$ LOD & $<$ LOD \\
\hline
\end{tabular}

The most prominent terpenes present in cannabis are $\alpha$-pinene, receptor CB2 at levels as low as <5mg/kg [18]. Similarly to CBD, it $\beta$-myrcene, limonene, linalool, $\beta$-caryophyllene, humulene and reduces neuropathic pain, and has anti-inflammatory and analgesic guaiol. $\beta$-caryophyllene, also a major terpenoid in black pepper, effects [19]. Humulene was detected in 17 samples (70.8\%), cinnamon and glove, was detected in 23 out of the 24 samples $\alpha$-pinene in 10 samples (41.7\%), $\beta$-myrcene in 9 samples (37.5\%), (95.8\%) at concentration levels ranging from $0.01-0.91 \mathrm{w} / \mathrm{w} \%$. limonene and linalool in 3 samples (12.5\%) and guaiol in 1 sample. $\beta$-caryophyllene acts as an agonist of peripheral cannabinoid Terpenoid contents are summarized in Table 3.

Table 3: Terpenoid content in CBD oil samples. Data expressed as the mean in percentage of dry starting material $(\mathrm{w} / \mathrm{w} \%)$.

\begin{tabular}{|c|c|c|c|c|c|c|c|}
\hline Cannabis Oil $\mathbf{n}^{\circ}$ & $\alpha$-Pinene & $\beta$-Myrcene & Limonene & Linalool & $\beta$-Caryophyllene & Humulene & Guaiol \\
\hline 1 & 0,227 & 0,119 & 0,39 & 0,044 & 0,119 & 0,002 & $<\mathrm{LOD}$ \\
\hline 2 & $<\mathrm{LOQ}$ & $<\mathrm{LOQ}$ & $<\mathrm{LOQ}$ & $<\mathrm{LOD}$ & 0,119 & 0,007 & $<\mathrm{LOD}$ \\
\hline 3 & $<\mathrm{LOQ}$ & $<\mathrm{LOQ}$ & $<\mathrm{LOQ}$ & $<\mathrm{LOQ}$ & 0,094 & $<$ LOQ & $<$ LOD \\
\hline 4 & $<\mathrm{LOQ}$ & $<\mathrm{LOQ}$ & $<\mathrm{LOQ}$ & $<$ LOD & 0,259 & 0,032 & $<$ LOD \\
\hline 5 & $<$ LOQ & $<$ LOD & $<\mathrm{LOQ}$ & $<$ LOD & 0,043 & $<$ LOQ & 0,008 \\
\hline 6 & 0,322 & 0,161 & 0,52 & 0,053 & 0,604 & 0,006 & $<$ LOD \\
\hline 7 & $<$ LOD & $<$ LOD & $<\mathrm{LOQ}$ & $<$ LOD & 0,152 & 0,015 & $<$ LOD \\
\hline 8 & 0,024 & 0,01 & $<\mathrm{LOQ}$ & $<\mathrm{LOD}$ & 0,909 & 0,053 & $<$ LOD \\
\hline 9 & $<\mathrm{LOQ}$ & $<\mathrm{LOQ}$ & $<\mathrm{LOQ}$ & $<$ LOD & 0,073 & 0,01 & $<\mathrm{LOQ}$ \\
\hline 10 & $<\mathrm{LOD}$ & $<$ LOD & $<\mathrm{LOQ}$ & $<$ LOD & 0,064 & 0,006 & $<$ LOD \\
\hline 11 & $<$ LOD & $<\mathrm{LOD}$ & $<\mathrm{LOQ}$ & $<$ LOD & 0,127 & 0,018 & $<\mathrm{LOD}$ \\
\hline 12 & 0,014 & 0,027 & $<\mathrm{LOQ}$ & $<$ LOD & 0,043 & 0,004 & $<\mathrm{LOD}$ \\
\hline 13 & $<$ LOD & $<\mathrm{LOD}$ & $<\mathrm{LOQ}$ & $<\mathrm{LOD}$ & 0,153 & 0,022 & $<$ LOD \\
\hline 14 & $<\mathrm{LOQ}$ & $<$ LOD & $<\mathrm{LOQ}$ & $<\mathrm{LOD}$ & 0,098 & $<\mathrm{LOQ}$ & $<$ LOD \\
\hline 15 & $<\mathrm{LOD}$ & $<$ LOD & $<\mathrm{LOQ}$ & $<\mathrm{LOD}$ & 0,03 & 0,005 & $<\mathrm{LOD}$ \\
\hline 16 & $<\mathrm{LOQ}$ & $<\mathrm{LOQ}$ & $<\mathrm{LOQ}$ & $<\mathrm{LOD}$ & 0,374 & 0,05 & $<\mathrm{LOD}$ \\
\hline 17 & $<$ LOD & $<$ LOD & $<\mathrm{LOQ}$ & $<$ LOD & 0,091 & 0,011 & $<$ LOD \\
\hline 18 & 0,064 & 0,019 & $<\mathrm{LOQ}$ & $<$ LOD & 0,687 & 0,033 & $<$ LOD \\
\hline 19 & 0,014 & $<\mathrm{LOD}$ & $<\mathrm{LOQ}$ & $<\mathrm{LOD}$ & 0,163 & 0,012 & $<\mathrm{LOD}$ \\
\hline 20 & 0,014 & 0,029 & $<\mathrm{LOQ}$ & $<$ LOD & 0,061 & $<\mathrm{LOQ}$ & $<$ LOD \\
\hline 21 & 0,015 & 0,033 & $<\mathrm{LOQ}$ & $<\mathrm{LOD}$ & 0,045 & $<\mathrm{LOQ}$ & $<$ LOD \\
\hline 22 & 0,005 & $<\mathrm{LOQ}$ & $<\mathrm{LOQ}$ & $<\mathrm{LOD}$ & 0,07 & 0,048 & $<\mathrm{LOD}$ \\
\hline 23 & $<\mathrm{LOD}$ & $<$ LOD & $<$ LOD & $<$ LOD & 0,01 & $<\mathrm{LOQ}$ & $<\mathrm{LOD}$ \\
\hline 24 & $<$ LOD & 0,1 & 0,13 & 0,02 & $<$ LOD & $<$ LOD & $<$ LOD \\
\hline
\end{tabular}




\section{Solvent content}

Traditionally, extraction using ethanol with or without heating was the method used to prepare cannabis tinctures. This method has the advantage of being simple and cheap, but only limited control over extraction selectivity is possible. The process results in extracts with higher concentrations in side products (chlorophyll, pigments and tannins) and the need of extra work-up to eliminate the extraction solvent. Today, supercritical $\mathrm{CO}_{2}$ extraction is the most popular preparation method. By controlling temperature and pressure, selective components of the plant material can be separated and collected from the bulk of the plant material. A total of 13 vendors gave information about the extraction method used. Out of them, five indicated cannabinoid extraction using a "raw" method, six indicated a $\mathrm{CO}_{2}$ extraction method and one claimed the use of both "raw" method and $\mathrm{CO}_{2}$. Organic solvents were found in four samples: cannabis oil $\mathrm{n}^{\circ} .7$ contained $2.70 \%$ of 2-propanol and oil $\mathrm{n}^{\circ} .15,17$ and 23 contained 1.05, 0.07 and $0.13 \%$ of ethanol, respectively. Probably, these four samples were prepared using traditional solvent extraction methods but none of the vendors informed about its use. Isopropanol is sometimes used to make tinctures for external use. Even if the concentrations found are low and do not pose a health risk, 2-propanol should not be used for the preparation of extracts intended for internal use as its major metabolite, acetone, is a central nervous system depressants [20].

\section{Pesticide content}

Pesticide regulation in commercial cannabis market is still a matter of debate [21]. Because cannabis remains an illegal plant in most countries, governmental regulations generally do not exist. In Europe the only notable exception is a Dutch regulation from 2002 containing policy guidelines for pesticides, herbicides and fertilizers stipulating that "All processes and procedures which may affect the quality of the product must be recorded in the documentation for each batch". While outdoor plantations generally do not need extensive pesticide or nutrient systems, indoor growers often use such products for pest control. Previous studies found fungicides, insecticides and acaricides in illegal cannabis plantations [22,23]. In our study, out of the 177 pesticides scanned, only propamocarb has been detected. It was semi-quantified in three samples: $n^{\circ} .4$ $(1.5 \mathrm{mg} / \mathrm{kg}), \mathrm{n}^{\circ} .11(2.0 \mathrm{mg} / \mathrm{kg})$ and $\mathrm{n}^{\circ} .22(1.5 \mathrm{mg} / \mathrm{kg})$. Propamocarb is a fungicide of low toxicity, used among others against canker caused by Pleosporales fungi. The levels detected in the 3 samples do not pose any health risk.

\section{Metal content}

Metals detected in the CBD oil samples are summarized in Table 4. Cannabis is known for its easy uptake of metals from soil [24] which makes it a promising plant for bioremediation. In our study, all metal concentrations were below the limits fixed by European legislation (Commission regulation (EC) No 1881/2006 of 19 December 2006 setting maximum levels for certain contaminants in foodstuffs): for cadmium (limit for vegetables: 0.05ppm), mercury (limit for fish as most contaminated food: $0.5 \mathrm{ppm}$ ), tin (limit of inorganic tin in infant formula: $50 \mathrm{ppm}$ ) or lead (limit in food complements: $3 \mathrm{ppm}$ ). Only one sample ( ${ }^{\circ}$. 15$)$ showed an abnormal high content of copper and zinc concentrations which may be explained by contamination during the extraction process using an organic solvent (ethanol) in copper containing vessles. However, these low toxicity elements are not posing serious health issue in this sample.

Table 4: Metal residues in medical cannabis extracts.

\begin{tabular}{|c|c|c|c|c|c|c|c|c|c|}
\hline Cannabis Oil $\mathbf{n}^{\circ}$ & As $(\mu \mathrm{g} / \mathrm{g})$ & Cd $(\mu \mathrm{g} / \mathrm{g})$ & $\operatorname{Cr}(\mu \mathrm{g} / \mathrm{g})$ & $\mathrm{Cu}(\mu \mathrm{g} / \mathrm{g})$ & $\mathrm{Hg}$ (ng/g) & $\mathrm{Ni}(\mu \mathrm{g} / \mathrm{g})$ & $\mathrm{Pb}(\mu \mathrm{g} / \mathrm{g})$ & $\operatorname{Sn}(\mu \mathrm{g} / \mathrm{g})$ & $\mathrm{Zn}(\mu \mathrm{g} / \mathrm{g})$ \\
\hline 1 & 0,03 & 0,01 & 0,15 & 15,48 & 0,46 & 0,41 & 0,36 & 0,11 & 7,6 \\
\hline 2 & 0,41 & $<$ LOD & 0,02 & 0,65 & 0,49 & 0,04 & 0,02 & 0,02 & 0,94 \\
\hline 3 & 0,09 & $<\mathrm{LOD}$ & 0,01 & 0,24 & 0,52 & 0,02 & $<$ LOD & 0,02 & 0,25 \\
\hline 4 & 0,21 & $<\mathrm{LOD}$ & 0,06 & 0,22 & 0,38 & 0,05 & 0,02 & 0,05 & 2,84 \\
\hline 5 & 0,03 & $<$ LOD & 0,01 & 0,06 & 0,92 & 0,03 & 0,02 & $<\mathrm{LOD}$ & 0,52 \\
\hline 6 & 0,02 & $<$ LOD & 0,02 & 0,67 & 1,96 & 0,06 & 0,03 & $<$ LOD & 3,19 \\
\hline 7 & 0,04 & 0,01 & 0,08 & 0,26 & 1,43 & 0,06 & 0,15 & 0,01 & 23,12 \\
\hline 8 & 0,02 & $<$ LOD & 0,04 & 0,1 & 0,43 & 0,06 & 0,02 & 0,03 & 0,75 \\
\hline 9 & 0,15 & $<$ LOD & 0,02 & 0,41 & 1,09 & 0,04 & 0,02 & 0,02 & 2,12 \\
\hline 10 & 0,11 & 0,01 & 0,03 & 0,37 & 1,21 & 0,07 & 0,04 & 0,02 & 0,22 \\
\hline 11 & 0,29 & $<$ LOD & 0,05 & 1,03 & 1,38 & 0,1 & 0,04 & 0,03 & 0,45 \\
\hline 12 & 0,01 & $<\mathrm{LOD}$ & 0,03 & 0,11 & 0,22 & 0,04 & 0,02 & $<$ LOD & 0,22 \\
\hline 13 & 0,22 & $<$ LOD & 0,03 & 0,18 & 1,32 & 0,04 & 0,03 & 0,01 & 4,64 \\
\hline 14 & 0,15 & $<$ LOD & 0,02 & 0,65 & 1,13 & 0,05 & 0,02 & 0,02 & 1,77 \\
\hline 15 & 0,02 & 0,02 & 0,04 & 88,87 & 0,36 & 0,35 & 0,74 & 0,51 & 42,57 \\
\hline 16 & 0,48 & $<$ LOD & 0,03 & 0,28 & 1,57 & 0,05 & 0,06 & 0,01 & 12,95 \\
\hline 17 & 0,03 & 0,01 & 0,28 & 0,18 & 1,83 & 0,15 & 0,23 & 0,05 & 2,81 \\
\hline 18 & 0,02 & 0,01 & 0,04 & 0,21 & 1,42 & 0,06 & 0,17 & 0,03 & 2,45 \\
\hline
\end{tabular}




\begin{tabular}{|c|c|c|c|c|c|c|c|c|c|}
\hline 19 & 0,02 & 0,01 & 0,08 & 0,24 & 0,44 & 0,07 & 0,03 & 0,02 & 0,4 \\
\hline 20 & 0,02 & $<$ LOD & 0,05 & 0,11 & 2,15 & 0,07 & 0,05 & 0,01 & 1,6 \\
\hline 21 & 0,02 & $<$ LOD & 0,02 & 0,1 & 0,31 & 0,06 & 0,03 & 0,01 & 13,6 \\
\hline 22 & 0,3 & 0,01 & 0,05 & 0,53 & 0,18 & 0,07 & 0,03 & 0,02 & 4,76 \\
\hline 23 & 0,32 & $<$ LOD & 0,03 & 0,07 & 0,89 & 0,04 & 0,04 & 0,02 & 0,48 \\
\hline 24 & 0,02 & <LOD & 0,02 & 0,14 & 0,35 & 0,05 & 0,03 & 0,01 & 0,5 \\
\hline
\end{tabular}

\section{Conclusion}

A total of 24 samples containing hemp extracts have been analyzed for cannabinoid, solvent, terpene, pesticide and metal contents. To the best of our knowledge, this is the first study to access user information and content control of commercial CBD oils. Most of the samples had substandard consumer information. Only four samples out of the 24 had overall information about expiration date, storage and dosage conditions, residual solvent content and possible side effects. All extracts contained CBD and/or CBDA but less than one third of the samples had total cannabidiol $(\mathrm{CBD}+\mathrm{CBDA})$ concentrations in the claimed concentration range. Pesticides were detected in 3 extracts and solvents in 4, all levels were in the non-toxic range. Also, all metal concentrations were below health concerns. There is no doubt that online commerce with cannabis-derived products (oil, powder, capsules, suppositories, chewing gum, soaps, skin lotions, cookies, ...) will become more and more popular as clinical evidence about its beneficial health effects for many different ailments keeps growing. Substandard products however, may, in the short term, be interesting for the vendors but, in the long term, may bring discredit to a highly beneficial product. However, not only producers and vendors are to blame as cannabis extracts are still in a legal grey zone. In most countries classification and consequently legalisation, are not clear and shifting somewhere between medication, herbal medicine, food supplement or novel food. Furthermore, some countries still register cannabis use offences, other have decriminalized its use, still others have increased penalties. Considering the impact, the products may have on consumer health, a harmonization of EU laws is highly desirable in order to clearly define its status and quality specifications, whether with or without psychotropic THC. Systematic testing of CBD extracts and all other cannabis-derived products should be mandatory for the benefice of the patients' health and honest CBD online retailers.

\section{Acknowledgment}

Anaïs Rodrigues is grateful to for financial support from one of the companies included in this study.

\section{Conflict of Interest}

Anais Rodrigues received financial support from one company included in the study. All other authors declare no conflict of interest.

\section{References}

1. Pisanti S, Malfitano AM, Ciaglia E, Lamberti A, Ranieri R, et al. (2017) Cannabidiol: State of the art and new challenges for therapeutic applications. Pharmacol Ther 175: 133-150.
2. VanDolah HJ, Bauer BA, Mauck KF (2019) Clinicians guide to cannabidiol and hemp oils. Mayo Clin Proc 94(9): 1840-1851.

3. Schrot RJ, Hubbard JR (2016) Cannabinoids: Medical implications. Ann Med 48(3): 128-141.

4. White CM (2019) A review of human studies assessing cannabidiol's (CBD) therapeutic actions and potential. J Clin Pharmacol 59(7): 923934.

5. Bergamaschi MM, Queiroz RH, Zuardi AW, Crippa JA (2011) Safety and side effects of cannabidiol, a cannabis sativa constituent. Curr Drug Saf 6(4): 237-249.

6. Huestis MA, Solimini R, Pichini S, Pacifici R, Carlier J, et al. (2019) Cannabidiol adverse effects and toxicity. Curr Neuropharmacol 17(10): 974-989

7. Russo EB (2011) Taming THC: Potential cannabis synergy and phytocannabinoid-terpenoid entourage effects. Br J Pharmacol 163(7): 1344-1364.

8. Paduch R, Kandefer M, Trytek M, Fiedurek J (2007) Terpenes: Substances useful in human healthcare. Arch Immunol Ther Exp 55(5): 315-327.

9. Tetali SD (2019) Terpenes and isoprenoids: A wealth of compounds for global use. Planta 249(1): 1-8.

10. Baert B, De Spiegeleer B (2010) Quality analytics of internet pharmaceuticals. Anal Bioanal Chem 398(1): 125-136.

11. Mackey TK, Nayyar G (2016) Digital danger: A review of the global public health, patient safety and cybersecurity threats posed by illicit online pharmacies. Br Med Bull 118(1): 110-126.

12. Vogel L (2017) Online pharmacy still open despite counterfeit allegations. CMAJ 189(31): E1023-E1024.

13. Kelly B (2015) Online pharmacies: Buyer beware. Aust Prescr 38(6): 186-187.

14. Fittler A, Bősze G, Botz L (2013) Evaluating aspects of online medication safety in long-term follow-up of 136 internet pharmacies: Illegal rogue online pharmacies flourish and are long-lived. J Med Internet Res 15(9): e199.

15. Qian Y, Gurley BJ, Markowitz JS (2019) The potential for pharmacokinetic interactions between cannabis products and conventional medications. J Clin Psychopharmacol 39(5): 462-471.

16. Stout SM, Cimino NM (2014) Exogenous cannabinoids as substrates, inhibitors, and inducers of human drug metabolizing enzymes: a systematic review. Drug Metab Rev 46(1): 86-95.

17. Jadoon KA, Tan GD, O'Sullivan SE (2017) A single dose of cannabidiol reduces blood pressure in healthy volunteers in a randomized crossover study. JCI Insight 2(12): e93760.

18. Fine PG, Rosenfeld MJ (2013) The endocannabinoid system, cannabinoids, and pain. Rambam Maimonides Med J 4(4): e0022.

19. Nuutinen T (2018) Medicinal properties of terpenes found in cannabis sativa and humulus lupulus. Eur J Med Chem 157: 198-228.

20. Slaughter RJ, Mason RW, Beasley D, Vale JA, Schep L (2014) Isopropanol poisoning. Clin Toxicol 52(5): 470-478. 
21. Subritzky T, Pettigrew S, Lenton S (2017) Into the void: Regulating pesticide use in colorado's commercial cannabis markets. Int J Drug Policy 42: 86-96.

22. Cuypers E, Vanhove W, Gotink J, Bonneure A, Van Damme P, et al. (2017) The use of pesticides in Belgian illicit indoor cannabis plantations. Forensic Sci Int 277: 59-65
23. Schneider S, Bebing R, Dauberschmidt C (2014) Detection of pesticides in seized illegal cannabis plants. Anal Methods 6(2): 515-520.

24. Ahmad R, Tehsin Z, Malik S, Asad S, Shahzad M, et al. (2016) Phytoremediation potential of hemp (Cannabis sativa L.): Identification and characterization of heavy metals responsive genes. Clean soil Air Water 44(2): 195-201

For possible submissions Click below: 